\title{
Stereoselective metabolism, distribution, and bioaccumulation brof triadimefon and triadimenol in lizards
}

\author{
Yinghuan Wang, Dingyi Yu, Peng Xu, Baoyuan Guo, Yanfeng Zhang, Jianzhong Li, \\ Huili Wang* \\ Research Center for Eco-Environmental Sciences, Chinese Academy of Sciences, 18 Shuangqing Road, Haidian District, Beijing 100085, PR China
}

\section{A R T I C L E I N F O}

\section{Article history:}

Received 6 February 2014

Received in revised form

3 June 2014

Accepted 19 June 2014

Available online 8 July 2014

Keywords:

Eremias argus

Triadimefon

Triadimenol

Stereoselectivity

\begin{abstract}
A B S T R A C T
In this research, Chinese lizards (Eremias argus) were chosen as laboratory animal to evaluate the stereoselectivity in the processes of metabolism, distribution, and bioaccumulation of triadimefon. A validated chiral high-performance liquid chromatography coupled with triple quadruple mass spectrometry (HPLC-MS/MS) method was developed for determining enantiomers' residues of parent compound triadimefon and its metabolite triadimenol in lizard blood and tissues. Pharmacokinetic results of single-does exposure suggested that $\mathrm{S}-(+)$-triadimefon was metabolized easier than $\mathrm{R}-(-)$-triadimefon, and RR-(+)-triadimenol was the main metabolic product of triadimefon. During the continuous exposure of two dose $\left(40 \mathrm{mg} / \mathrm{kg}^{\mathrm{bw}} \cdot \mathrm{d}\right.$ and $\left.200 \mathrm{mg} / \mathrm{kg}^{\mathrm{bw}} \cdot \mathrm{d}\right)$, enantiomers of triadimefon and triadimenol were detected in all body compartments, with the highest triadimefon concentrations in brain. However, the triadimenol concentrations were not significantly different among the compartments. The concentrations of RS- $(+)$-triadimenol were negative correlated with concentrations of $\mathrm{RR}-(+)$-triadimenol both in blood $(r=-0.775, p=0.024)$ and liver $(r=-0.834, p=0.02)$ in $200 \mathrm{mg} / \mathrm{kg}^{\mathrm{bw}} \cdot \mathrm{d}$ group, which indicates that chiral conversion between enantiomers of triadimenol might exist in the metabolic process of triadimefon. In all the processes, the enantiomer fractions (EFs) of R-( - )-triadimefon and RR-(+)-triadimenol were significantly different from their natural ratios, 0.5 and 0.1 , respectively, which proved that metabolism, bioaccumulation, and distribution of triadimefon and triadimenol in lizards were enantioselective. These results help enrich and supplement the knowledge of the stereoselective behaviour of triadimefon and triadimenol in reptile.
\end{abstract}

(c) 2014 Elsevier Inc. All rights reserved.

\section{Introduction}

Pesticides are widely adopted in agriculture to control pest damage to crops and raise production. However, there is proof that the residues of some pesticides and their metabolites cause environment problems (Randhawa et al., 2014). Triadimefon and triadimenol are two registered broad-spectrum systemic fungicides, and extensively used in the field (Crowell et al., 2011). Triadimefon (TF) [(RS)-1-(4-chlorophenoxy)-3, 3-dimethyl-1(1H-1, 2, 4-triazol-1-yl) butan-2-one, CAS NO: 43121-43-3] has been commonly used for the control of mildews and fungi on food crops, turf grasses, shrubs, and trees (Roberts and Hutson, 1999). Triadimenol (TN) [(1RS, 2RS; 1RS, 2SR)-1-(4-chlorophenoxy)-3, 3dimethyl-1-(1H-1, 2, 4-triazol-1-yl) butan-2-ol, CAS NO: 55219-65-3], a metabolite of triadimefon, has greater fungicidal activity than TF (Liang et al., 2013). TF and TN enter into the soil ecosystem because of direct spraying on the soil surface during agriculture

\footnotetext{
*Corresponding author. Fax: +86162849790.

E-mail address: huiliwang@rcees.ac.cn (H. Wang).
}

application, which poses potential danger to the animals living in the soil. Previous studies showed that TF and TN have clear teratogenic effects on the bronchial arches and cranial nerves of rat embryos (Menegola et al., 2000). TF and TN are also harmful to mammalian central nervous system and are neurotoxins in rats, mice, and rabbits (U.S. Environmental Protection Agency (U.S. EPA), 2006; Walker et al., 1990). These two fungicides have been categorized as "possible human carcinogens" (U.S. Environmental Protection Agency (U.S. EPA), 2006).

Pesticides have been considered as one of the major factors contributing in the global decline of reptiles (Gibbon et al., 2000). Past attention was focused on measuring body burdens of various pollutants to wild reptiles which gave an understanding of historical exposure of given populations (Buono et al., 2007; Holem et al., 2008; Mann et al., 2007; Moss et al., 2009; Trinchella et al., 2006; De Falco et al., 2007; Keller et al., 2006; Simoniello et al., 2010; van de Merwe et al., 2010). However, the population-level effects and actual risks of pollutants on reptiles are still generally understudied (Weir et al., 2010). In soil, TF is easily decomposed and converted to TN with a halflife of 6-30 days (Petrovic et al., 1993; Singh, 2005). As a comparison, TN exhibits a much longer persistence (soil half-life $>240$ days) 
(Bromilow et al., 1999). Because the abuse of triazole pesticides in China (Lin et al., 2008), these two triazole pesticides may be transported from cultivated soils in significant amounts especially TN, which post threats to the life in soils. However, to our knowledge, there is no known research on the toxicity of these two compounds to reptiles. Reptiles are remaining as the least studied vertebrates in ecotoxicology (Hopkins, 2000).

In order to fill the gap in this research area, Chinese lizards (Eremias argus) were used in this study to evaluate the acute and chronic effects of TF and TN on reptiles. Lizards are regarded as one of the significant ecological animals in agriculture systems because they prey on crop pests. E. argus are widely distributed in the north of Yangtze River including North China Plain and Northeast China Region, the main agricultural areas in China. Excessive usage of TF and TN in these areas (Lin et al., 2008) has been a direct threat to the E. argus.

About 30 percent of the organic agrochemicals are chiral compounds and consist of two or more enantiomers, which have identical physic-chemical properties (Ulrich et al., 2012). Nevertheless, the bioactivity, toxicity, metabolism, excretion, distribution, and bioaccumulation of these enantiomers may be entirely different (Williams, 1996). The enantiomers of chiral pesticides could be different when binding to structure-sensitive biological receptors and naturally occurring chiral biomolecules because of their different molecular configurations (Dong et al., 2013). Stereoselectivity in the processes of absorption, distribution, metabolism, and bioaccumulation in organisms may result in ecotoxicological effects that are beyond the traditional knowledge that treat them as single compounds in risk assessment (Buser et al., 2002; Dong et al., 2013; Wong, 2006). TF has one chiral center and consists of an equimolecular mixture of the two enantiomers while TN has two chiral centers and consists of four stereoisomers including two pairs of diastereomers. The biotransformation of TF into TN is stereoselective and the biological response of each TN stereoisomer is different (Deas et al., 1986; Garrison et al., 2011; Spindler and Fruh, 1998) (Fig. 1). The stereoselective formation of TF and TN is an important issue in ecological risk assessment when considering the difference in fungicidal activity and toxicity among the enantiomers ( $\mathrm{Li}$ et al., 2014). Stereoselective metabolism of TF to TN has been observed in soil microorganisms and rainbow trout (Garrison et al., 2011;
Kenneke et al., 2010; Li et al., 2011). Unfortunately, the stereoselectivity of TF and TN in reptiles have never been studied.

To describe actual environmental fate and ecological risks from a complete view, and understand environmental impact of these pesticides, it is crucial to study the stereoselective behaviors of chiral pesticides. In this study, the experiments were conducted to obtain a better understanding of the biological fate of the TF and TN enantiomers in lizard blood on a single acute exposure and assess the stereoselective metabolism, distribution and bioaccumulation of TF and TN in different tissues in lizards on the continuously exposure. The results complement the knowledge of the stereoselectivity of chiral pesticides in reptiles, and are instructive for future TF and TN toxicity study on reptiles.

\section{Materials and methods}

\subsection{Chemicals and reagents}

Racemic TF (99.55 percent) and TN (99.1 percent), analytical standards of TN-A (racemate of RS- and SR-enantiomer, 99.9 percent purity) and TN-B (racemate of RR- and SS-enantiomer, 99.9 percent purity) were kindly provided by College of Science, China Agricultural University (Beijing, China) (Liang et al., 2012). Stock solutions of TF and TN were prepared in methanol (HPLC grade, Dikma, USA) at $1000 \mathrm{mg} / \mathrm{L}$ and kept in dark at $-20^{\circ} \mathrm{C}$.

\subsection{Dosing}

Dosing was prepared according to those described previously with modifications (Di Renzo et al., 2009; McFarland et al., 2011, 2009; Suski et al., 2008). TF was first dissolved in the ethanol (analytical grade, Beijing Chemical Reagent Co. Ltd, China) then dispersed in corn oil (ethanol:corn oil was 1:9, v/v). Test preparations were stored in dark at $4{ }^{\circ} \mathrm{C}$ until use to prevent compound degradation. The corn oil-ethanol lactescence were warmed to room temperature $\left(25^{\circ} \mathrm{C}\right)$ and continually mixed by magnetic stirring apparatus (90-1, Shanghai ZhenRong Scientific Instrument Co. Ltd, China) before dosing. The micro injector was used to oral inject a volume of $20-50 \mu \mathrm{L}$ corn oil or corn oil-ethanol lactescence.

\subsection{Test lizard and culture conditions}

The juvenile E. argus were collected in Abag Banner, Inner Mongolia (China) and maintained in laboratory since July 2009. Lizards were kept in $5 \times 1.2 \times 0.4 \mathrm{~m}$ solid bottom indoor aquarium covered with $10 \mathrm{~cm}$ mollisol and fallen leaves. The

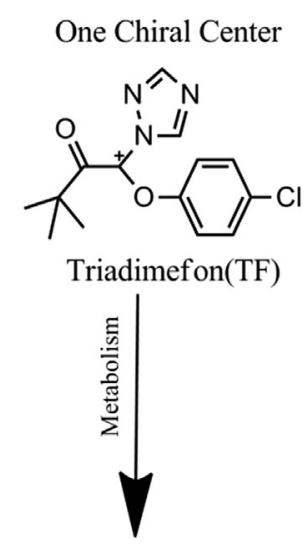

Two Chiral Center<smiles>CC(C)(C)[C@H](Oc1ccc(Cl)cc1)n1cncn1</smiles>

Triadimenol(TN)
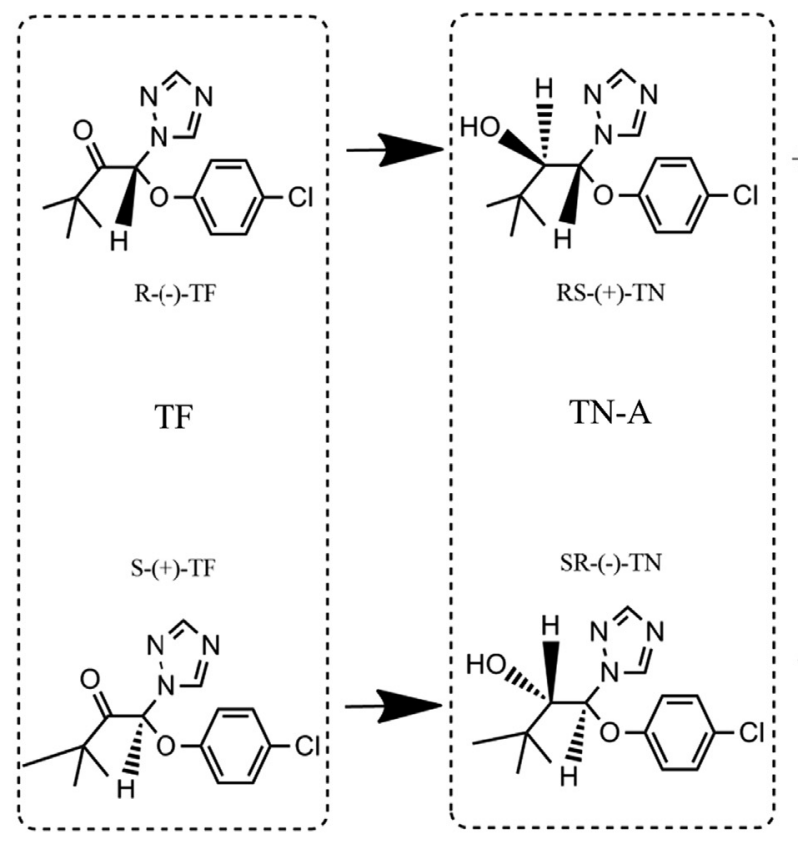

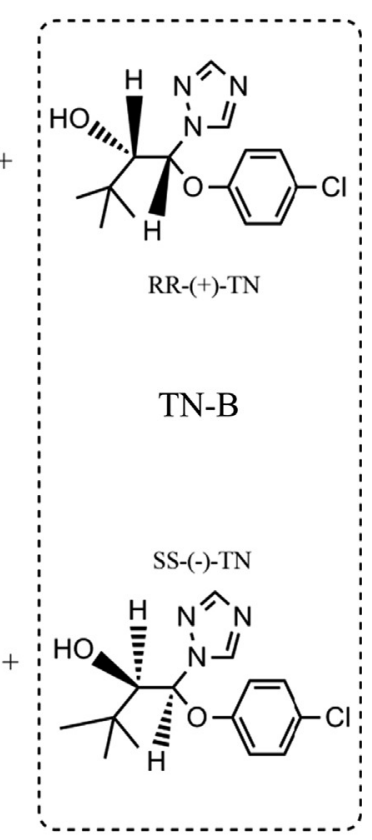

Fig. 1. The metabolic transformation of TF to TN and the enantiomers of TF and TN. 
temperature and humidity were maintained at $25-30{ }^{\circ} \mathrm{C}$ and $30-60$ percent. Daylight lamps $(100 \mathrm{~W})$ were set to a $14: 10 \mathrm{~h}$ light:dark photoperiod to provide enough light and maintain the needed temperature. Lizards were fed with mealworms (Tenebrio molitor) twice a day. The water was sprayed every other day and the excreta and residues were cleaned twice a week.

The sexually mature lizards ( $3-3.5 \mathrm{~g}, 2-3$ years old) used in the experiment were randomly divided into several groups of 10 lizards (sex ratio 1:1). Each group was housed in $30 \times 30 \times 20 \mathrm{~cm}$ glass cage with a water dish. The experimental conditions were the same as the rearing condition. Each lizard was fed two mealworms (about $1.0 \mathrm{~cm}$ each) per day.

Animal welfare and experimental procedures were carried out in accordance with the Guide for the Care and Use of Laboratory Animals (Ministry of Science and Technology of China, 2006). The animal care and use procedures were approved by Research Center for Eco-Environmental Sciences, CAS.

\subsection{Preliminary acute and subacute experiments}

Preliminary acute study was conducted according to previous research to find out the safe concentration to carry out the subacute experiment (Feder et al., 1991; U.S. Environmental Protection Agency (U.S. EPA), 1996a, 1996b; Organization for Economic Cooperation and Development (OECD), 1984). Control group, vehicle control group and four treatment groups (Total 6 groups, each group $n=10$ ) were used in the acute study. In each group, the dose was delivered orally to each individual. Each lizard was independent and it is appropriate to consider these as replicates (same in further experiments). Four experimental dose ranges $(2,20$, $200,2000 \mathrm{mg} / \mathrm{kg}^{\mathrm{bw}}$ ) were selected. Lizards were administered orally once and responses were recorded during a 7-day observation period. The $1 / 10$ of the maximum non-lethal dose in acute study was chosen as the highest dose in subacute experiment.

A subacute experiment was conducted to find out the safe concentration to carry out further experiments. The control group, vehicle control group and three treatment groups (Total 5 groups, each group $n=10$ ) were used in 14-day subacute experiments. Three experimental dose ranges $\left(40,90,200 \mathrm{mg} / \mathrm{kg}^{\mathrm{bw}} \cdot \mathrm{d}\right)$ were selected based on results from the acute study. Doses were administered daily for 14 consecutive days with dose adjusted the body weight of each lizard. All signs of intoxication, other abnormal behaviour, and mortality were recorded. The maximum non-lethal dose in subacute study was chosen as the highest dose in metabolism, distribution, and bioaccumulation exposure.

\subsection{Metabolism, distribution, bioaccumulation, and restoring experiment}

Two experimental dose ranges $\left(40,200 \mathrm{mg} / \mathrm{kg}^{\mathrm{bw}}\right)$ were selected based on results from the subacute study for the further experiments.

Metabolism experiment was conducted using 54 new lizards (27 lizards for each dose). Each lizard was administered orally once. Blood samples were collected at $2,6,8,12,24,48,72,120$ and $168 \mathrm{~h}$ after lizards were dosed. Three lizards were euthanized with carbon dioxide randomly for each dose group at once.

Considering the possible death of lizards during the exposure period, a distribution experiment was conducted using 10 new lizards (5 lizards for each dose). These lizards were continuously administered of TF daily for 14 days with dose adjusted according to the body weight. All lizards were euthanized with carbon dioxide after 14 days of exposure. Each lizard's blood, brain, heart, lungs, liver, kidneys, and intestines were collected for concentration analysis of enantiomers of TF and TN.

A chronic bioaccumulation experiment was conducted using 80 new lizards (40 lizards for each dose). New lizards were continuously administered of TF daily for 35 days with dose adjusted according to the body weight. Lizards were euthanized with carbon dioxide at 1, 3, 5, 7, 10, 14, 21, 28, 35 days. Blood and liver samples were collected for concentration analysis of enantiomers of TF and TN. Three lizards were euthanized randomly from each group at once.

A restoring experiment was conducted using 50 lizards (25 lizards for each dose). These lizards were first administered of TF daily for 14 days with dose adjusted the body weight. Then these lizards were stopped exposing under TF and fed normally for 14 days. Lizards were euthanized with carbon dioxide at 1, 2, 3, 5, 7, 10, 14 days in normal feeding. Blood and liver samples were collected for concentration analysis of enantiomers of TF and TN. Three lizards were selected at randomly from each group and were simultaneously euthanized.

\subsection{HPLC-MS/MS conditions}

HPLC was performed using Thermo ACCELA series (Thermo Electron Corporation, Hopkinson, MA) equipped with ACCELA Autosampler, ACCELA 600 pump, a $20 \mu \mathrm{L}$ injection loop, and a $2 \mu \mathrm{L}$ flow cell. Enantiomers were separated on a Phenomenex Lux Cellulose- 1 column $(250 \times 4.6 \mathrm{~mm}$ id, $5 \mu \mathrm{m}$ particles $)$, packed with CSP of CDMPC and obtained from Guangzhou FLM Scientific Instrument (Guangzhou, China). The mobile phase was a mixture of 73 percent methanol, 27 percent water with a flow rate of $0.5 \mathrm{~mL} / \mathrm{min}$. Chromatographic separation was conducted at $20^{\circ} \mathrm{C}$, and the injection volume was $10 \mu \mathrm{L}$. TSQ QUANTUM ACCESS
MAX was used for LC-MS/MS analysis (Thermo Electron Corporation, Hopkinson, MA). Quantification was achieved in positive-ion mode (ESI+). The signals were received and processed with Thermo Xcalibur 2.2 SP1.48 software. The optimized major working parameters were as follows: Spray Voltage $3200 \mathrm{~V}$, Vaporizer Temperature $250{ }^{\circ} \mathrm{C}$, Sheath Gas Pressure $30 \mathrm{psi}$, Aux Gas Pressure 10 arbitrary units, Capillary Temperature $350^{\circ} \mathrm{C}$, Capillary Offset 35 V, Q2 Collision Gas Pressure 1.5 mTorr. Multiple reactions monitoring mode was used; the precursor and product ions of TF and TN with corresponding declustering potentials and collision energies are summarized in Supporting Information Table S1.

\subsection{Extraction procedure}

Whole blood (50-100 $\mu \mathrm{L})$ or homogenized tissue matrix (0.01-0.03 g) was transferred into a 2-mL polypropylene centrifuge tube and added with $2 \mathrm{~mL}$ acetonitrile (analytical grade, Beijing Chemical Reagent Co. Ltd, China). The mixture was vortex-mixed for $3 \mathrm{~min}$, exposed to ultrasonic vibration for $20 \mathrm{~min}$ and then centrifuged at $10,000 \mathrm{r} / \mathrm{min}$ for $5 \mathrm{~min}$. The supernatants were transferred to a separator funnel. The sample was re-extracted in the same way and the supernatants were combined. Five $\mathrm{mL} n$-hexane (HPLC grade, Dikma, USA) was added for liquid-liquid partition to extract most of lipid. The upper layer of $n$-hexane was discarded, and the layer of acetonitrile was collected and evaporated to near dryness with a vacuum rotary evaporator at $30^{\circ} \mathrm{C}$ under a gentle nitrogen stream. The residue was re-dissolved in $1 \mathrm{~mL}$ of methanol and filtered through a $0.22-\mathrm{mm}$ filter into a sample vial for HPLC-MS/MS analysis.

\subsection{Data and statistical analysis}

The enantiomer fraction (EF) was used to measure the enantioselectivity of the bioaccumulation of TF enantiomers (Eq. (1)).

$\mathrm{EF}=$ concentration of $\frac{(-)}{(-)+(+)}$

The $\mathrm{EF}$ values defined range from 0 to 1 , with $\mathrm{EF}=0.5$ representing the racemic mixture.

Each diastereomer of TN is a racemic mixture. TN-A is 80 percent of the total triadimenol, while TN-B is about 20 percent (Detail shown in Part 3.1). The EF measured for each of the four triadimenol stereoisomers are calculated according to Eq. (2) (Kenneke et al., 2010).

$\mathrm{EF}=$ concentration of $\frac{\text { enatiomer } x}{\text { sum of } 4 \text { enatiomers }}$

Pharmacokinetic parameters were calculated in one dose experiment. The concentrations of TF enantiomers of blood sample would decline after the concentrations reached their maximum value. The TF release pattern was in accorded with the first order kinetics. The relation between concentrations of TF enantiomers $(C)$ and the sampling time $(t)$ was calculated according to Eq. (3).

$\lg C=-\frac{k t}{2.303+b}$

The half-life period $t_{1 / 2}$ of TF enantiomers was calculated according to Eq. (4)

$t_{1 / 2}=\frac{0.693}{k}$

Area under curve $\left(\mathrm{AUC}_{0_{-} t}\right)$ was calculated by trapezoidal rule. Injected dose $(D)$ was considered as total drug concentration. Blood clearance (CL) was expressed on Eq. (5).

$\mathrm{CL}=\frac{D}{\mathrm{AUC}_{0-t}}$

SPSS 16.0 was used for statistics analysis. All the other values in the text were presented as mean $\pm \mathrm{SD}$. A $t$-test was used to show the difference between the means of EF (TF1) or EF (TN4) and its nature ratio. A paired-samples $t$-test was used to determine the difference of the means of EF (TF1) or EF (TN4) between two exposure groups or any two of the tissues (including blood). One-way ANOVA were performed to analyze the significant differences of enantiomer concentrations among the tissues (including blood). Significant difference existed while $p<0.05$.

\section{Results and discussion}

\subsection{Method validation}

Enantiomers of $\mathrm{TN}$ and TF were baseline-resolved under the optimized condition. Fig. 2 shows the pattern of a commercial mixture of triadimenol chromatographic separation of TN-A and TN-B, each of which shows two enantiomer peaks in equal amounts (1 and 2, 3 and 4). Each diastereomer is a racemic mixture. TN-A is 80 percent of the 
total triadimenol, while TN-B is about 20 percent. Liang et al. (2012, 2013) confirmed elution order. Enantiomer peaks were shown in Fig. 2. (1) SR-(-)-TN (TN1); (2) RS-(+)-TN (TN2); (3) SS-(-)-TN (TN3); (4) RR-(+)-TN (TN4); (5) R-( - )-TF (TF1); (6) S-(+)-TF (TF2). Linear calibration curves were obtained over the concentration range of $0.001-1 \mathrm{mg} / \mathrm{L}$ for TN1 $(y=1.7222300 x+68,045, r=0.9994)$, TN2 $(y=16934700 x+77,529, r=0.9994)$, TN3 $(y=1757710 x+12,802, r=$ $0.9997)$, TN4 $(y=2251540 x+16,282, r=0.9987)$, TF1 $(y=15752600 x+$ $44,686, r=0.9997)$, TF2 $(y=14791300 x+31,392, r=0.9998)$. Recovery evaluation was carried out with six replicates at three fortified concentration levels. The concentration levels were $0.01,0.1$, and $1 \mathrm{mg} / \mathrm{kg}$ (mg/L for blood) for TF enantiomers; 0.008, 0.08, and $0.8 \mathrm{mg} / \mathrm{kg}$ ( $\mathrm{mg} / \mathrm{L}$ for blood) for TN-A stereoisomers, 0.002, 0.02, and $0.2 \mathrm{mg} / \mathrm{kg}$ ( $\mathrm{mg} / \mathrm{L}$ for blood) for TN-B stereoisomers. Recoveries of each enantiomer ranged from 88 to 107 percent. The precision of the assay for each enantiomer ranged from 2.5 to 12.8 percent (RSD). LODs were $0.003 \mathrm{mg} / \mathrm{kg}$ in lizard tissues and $0.002 \mathrm{mg} / \mathrm{L}$ in lizard bloods for the 2 enantiomers of TF. The LODs were $0.002 \mathrm{mg} / \mathrm{kg}$ in lizard tissues and $0.002 \mathrm{mg} / \mathrm{L}$ in lizard bloods for the 2 enantiomers of TN-A. The LODs were $0.0007 \mathrm{mg} / \mathrm{kg}$ in lizard tissues and $0.0006 \mathrm{mg} / \mathrm{L}$ in lizard bloods for the 2 enantiomers of TN-B. The LOQs were established as being $0.01 \mathrm{mg} / \mathrm{kg}(\mathrm{mg} / \mathrm{L})$ for TF enantiomers, $0.008 \mathrm{mg} / \mathrm{kg}(\mathrm{mg} / \mathrm{L})$ for TN-A stereoisomers, $0.002 \mathrm{mg} / \mathrm{kg}(\mathrm{mg} / \mathrm{L}$ ) for TN-B stereoisomers based on the minimum fortified concentration level in lizard tissues and bloods. The stereoselective HPLC-MS/MS method described in this investigation was validated for simultaneous separation and determination of TF and TN stereoisomers in lizards.

\subsection{Preliminary acute and subacute experiments}

Systemic signs of toxicity were observed in the acute experiments. Anorexia, lethargy, and drumble occurred in $2000 \mathrm{mg} / \mathrm{kg}^{\mathrm{bw}}$ group. Signs of recovery were showed at day 5 after dosed. TF can produce hyperactivity in both mice and rats, repeated treatment with TF can lead to behavioral sensitization (Reeves et al., 2004, 2003), but those signs weren't observed in this study. No death occurred in all four groups. According to the avian oral toxicity test guidelines of U.S. Environmental Protection Agency (U.S. EPA) (1996a, 1996b), Organization for Economic Cooperation and Development (OECD) (1984), a chemical could be recognized as low acute oral toxicity while there is no mortality occurred at the limit test of $2000 \mathrm{mg} / \mathrm{kg}^{\text {bw }}$. TF could be recognized as low acute

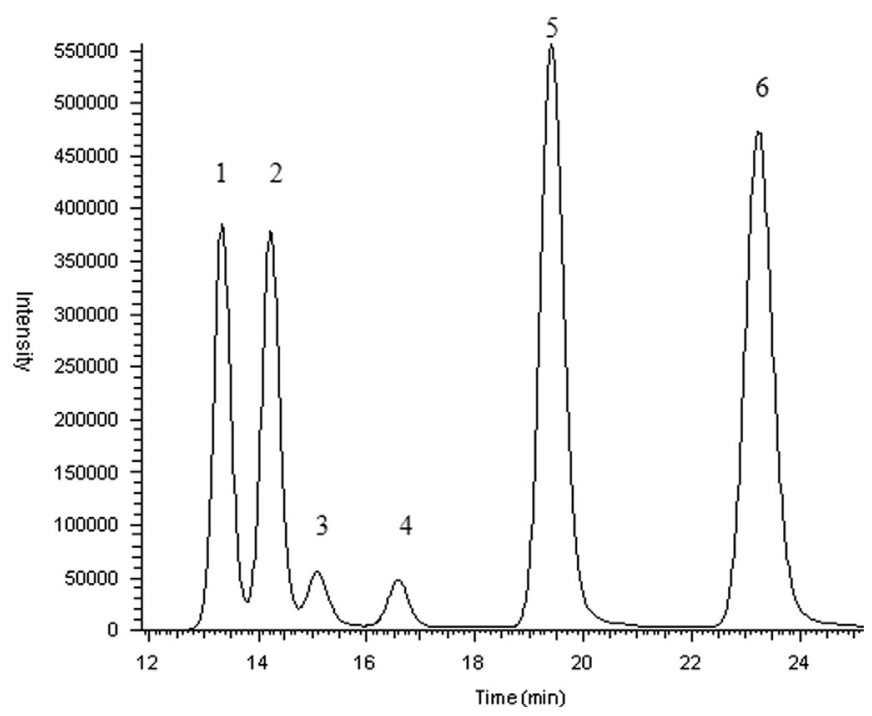

Fig. 2. Simultaneous stereoselective separation of TF and TN. $0.5 \mathrm{mg} / \mathrm{L}$ for each racemate of TF and TN: (1) SR-( - )-TN (TN1); (2) RS-(+)-TN (TN2); (3) SS-( - )-TN (TN3); (4) RR-(+)-TN (TN4); (5) R-( - )-TF (TF1); (6) S-(+)-TF (TF2). oral toxicity to E. argus. Dosage of $200 \mathrm{mg} / \mathrm{kg}^{\text {bw }}$ (1/10 of $2000 \mathrm{mg} /$ $\mathrm{kg}^{\mathrm{bw}}$ ) was chosen as the highest dose in subacute experiment.

Three groups 40, 90 and $200 \mathrm{mg} / \mathrm{kg}^{\text {bw }}$. d were relatively safe feeding concentrations in the subacute experiment according to the result of acute experiment. Anorexia and lethargy occurred at the first 3 days, movement and food consumed were recovered at approximately day 5 . Only one lizard died in $90 \mathrm{mg} / \mathrm{kg}^{\mathrm{bw}}$. d group at day 7 , therefore, $200 \mathrm{mg} / \mathrm{kg}^{\mathrm{bw}}$. $\mathrm{d}$ (maximum no-death dosage) was chosen as the highest dose to carried out the metabolism, distribution and bioaccumulation exposure.

\subsection{Metabolism in lizard blood}

Changes in the concentrations of racemic parent compound TF and its metabolic product TN in single oral injection of rac-TF were studied (Fig. 3). Concentrations of TF1 and TF2 reached their maximum value at $6 \mathrm{~h}$ after administration of rac-TF in $40 \mathrm{mg} /$ $\mathrm{kg}^{\text {bw }}$ group. However, the time reduced to $2 \mathrm{~h}$ in $200 \mathrm{mg} / \mathrm{kg}^{\mathrm{bw}}$ group. Concentrations of metabolic products TN1, TN3, TN4 reached their maximum value at the 4th hour; concentrations of TN2 reached their maximum value at the 6-8th hour in both groups. These indicated that rac-TF might be absorbed and metabolized rapidly. When the dosage exceeded a level beyond metabolic ability, concentrations of TF1 and TF2 reach their maximum value immediately.

Pharmacokinetic results were shown in Table 1 . The $t_{1 / 2}$ of TF1 and TF2 was 2.33 and $1.98 \mathrm{~h}$ in low dose group, 2.84 and $2.71 \mathrm{~h}$ in high dose group, respectively. The clearance rate of TF1 and TF2 was 2.30 and $3.13 \mathrm{~L} / \mathrm{h}$ in low dose group, 7.39 and $10.04 \mathrm{~L} / \mathrm{h}$ in high dose group, respectively. The concentrations of TF1 were little higher than its antipode in the blood, a t-test was carried out to compare the means of the EF values of TF1 in blood samples with 0.5 . The average $\operatorname{EF}(\mathrm{TF} 1)$ was $0.568(p=0.007)$ in low dose group and the average $\operatorname{EF}(\mathrm{TF} 1)$ was $0.568(p=0.009)$ in high dose group, respectively. These suggested that TF2 was easier metabolized and eliminated than TF1 in lizard blood.

A difference was observed that the concentrations of TN4 were much higher than other enantiomers. As shown in Fig. 2, the content of TN4 was only half of TN-B and 10 percent of the provided mixture of TN. A t-test was carried out to compare the means of the EF values of TN4 in blood samples with 0.1. The average $\mathrm{EF}(\mathrm{TN} 4)$ was $0.804(p<0.001)$ in low dose group and the average $\operatorname{EF}(\mathrm{TN} 4)$ was $0.739(p<0.001)$ in high dose group. These indicated that the metabolism of TF was stereoselective and TN4 was the main metabolic product.

It is reported that $(-)-\mathrm{TF}$ (TF1) was 2-fold more toxic than the racemate, while the $(+)-\mathrm{TF}(\mathrm{TF} 2) \mathrm{LC}_{50}$ fell in between the racemate and TF1 values (Kellock et al., 2009). TN-A is about 10 times more acutely toxic to rats than triadimenol-B (World Health Organization, 2006). The toxicity of TF and TN enantiomers is different. Because of metabolizing to TN rapidly, the ecotoxicology effects of TF we discussed in the paper were actually the combination of all the enantiomers of these two compounds. Due to our experimental set ups, we could not differentiate the effects of individual enantiomers. These effects are worthy of future study.

\subsection{Tissue distribution}

The final residues of all enantiomers of TF and TN were detected in tissue and blood samples at day 14 in both groups (Supporting Information, Fig. S2). T-test was carried out to compare the means of the $\mathrm{EF}(\mathrm{TF} 1)$ and $\mathrm{EF}(\mathrm{TN} 4)$ values in different tissues with $\mathrm{EF}(\mathrm{TF} 1)=0.500$ and $\mathrm{EF}(\mathrm{TN} 4)=0.100$ (Supporting Information Table S2). The means of the EF(TF1) values in different tissues are extremely significant difference with 0.5 , which indicated that stereoselective distribution of TF enantiomers and its 
a
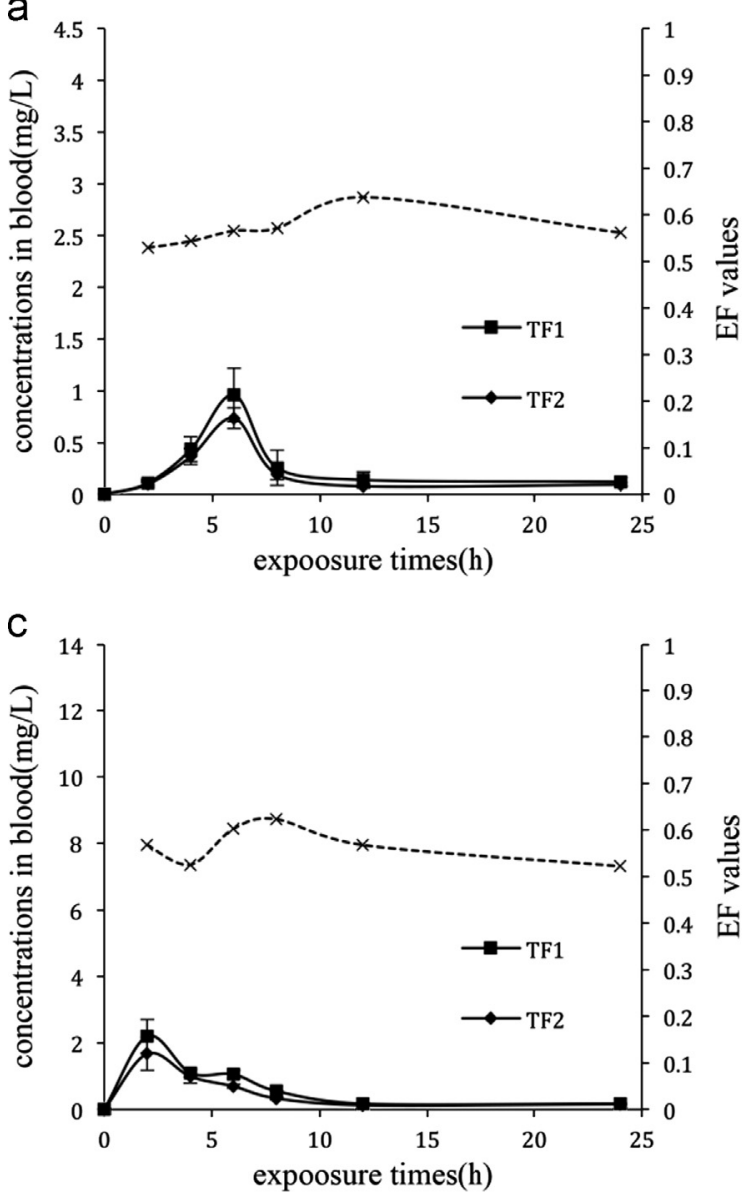

b

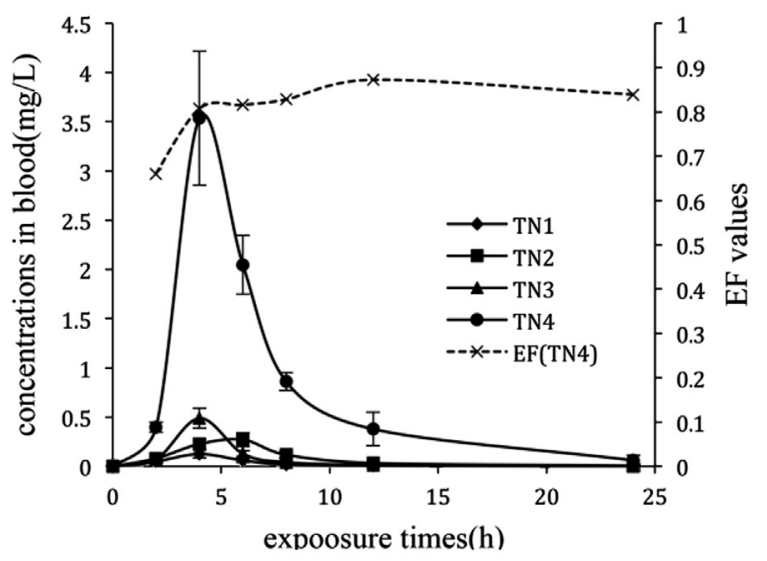

d

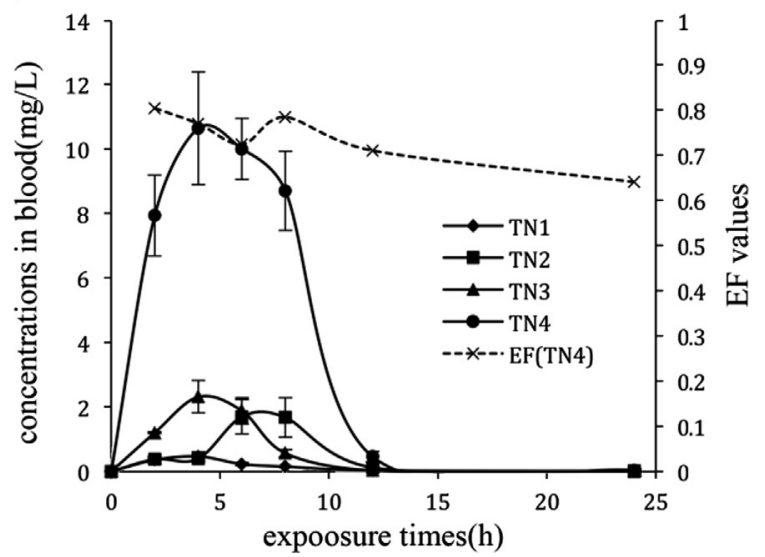

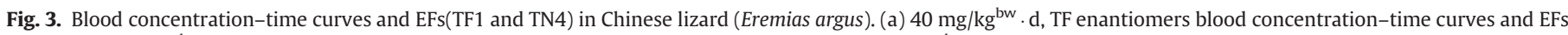

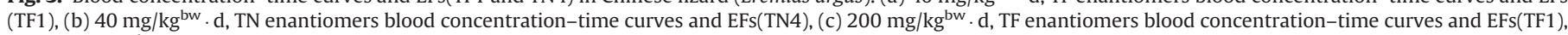
(b) $200 \mathrm{mg} / \mathrm{kg}^{\mathrm{bw}} \cdot \mathrm{d}$, TN enantiomers blood concentration-time curves and EFs(TN4). TF1 represents the R-( - )-TF, TN4 represents the RR-(+)-TN.

Table 1

Pharmacokinetic parameters of enantiomers after administration with rac-TF in lizard blood.

\begin{tabular}{|c|c|c|c|c|}
\hline \multirow[t]{2}{*}{ Pharmacokinetic parameters } & \multicolumn{2}{|l|}{$40 \mathrm{mg} / \mathrm{kg}^{-\mathrm{bw}}$} & \multicolumn{2}{|l|}{$200 \mathrm{mg} / \mathrm{kg}^{-\mathrm{bw}}$} \\
\hline & TF1 & TF2 & TF1 & TF2 \\
\hline First-order kinetics equation & $y=-0.1287 x+0.6293$ & $y=-0.1518 x+0.6672$ & $y=-0.1059 x+0.0 .5567$ & $y=-0.1112 x+0.0 .4545$ \\
\hline$R^{2}$ & 0.8478 & 0.9083 & 0.9679 & 0.9932 \\
\hline$k$ & 0.2964 & 0.3496 & 0.2439 & 0.2561 \\
\hline$t_{1 / 2}(\mathrm{~h})$ & 2.338 & 1.982 & 2.841 & 2.706 \\
\hline $\mathrm{AUC}_{(0-24)}(\mathrm{mg} / \mathrm{L} \mathrm{h})$ & 5.656 & 4.200 & 12.847 & 9.780 \\
\hline $\operatorname{AUC}_{(0-t)}(\mathrm{mg} / \mathrm{L} \mathrm{h})$ & 17.42 & 12.80 & 27.08 & 19.92 \\
\hline $\mathrm{CL}(\mathrm{L} / \mathrm{h})$ & 2.296 & 3.125 & 7.386 & 10.04 \\
\hline
\end{tabular}

metabolic product TN enantiomers were occurred in different tissues of lizard. In the four enantiomers of TN, the proportion of TN4 was from 53.5 to 79.6 percent in different tissues. In addition, the means of the EF(TF4) values are extremely significant difference with 0.1 . These results meant that the concentrations of TN4 were much higher than other three enantiomers in all tissues. TN4 was also the main metabolic product of TF in lizard tissues.

A one-way ANOVA test was carried out to compare the difference of TF and TN concentrations among lizard tissues. During the exposure of $40 \mathrm{mg} / \mathrm{kg}^{\mathrm{bw}} \cdot \mathrm{d}$, both TF1 and TF2 concentrations in organs were in the following order: brain $>$ intestine $>$ heart $>$ kidney $>$ lungs $>$ liver, while under the exposure of $200 \mathrm{mg} / \mathrm{kg}^{\text {bw }} \cdot \mathrm{d}$, the order of TF enantiomers concentrations changed to: brain $>$ liver $>$ kidney $>$ heart $>$ lungs $>$ intestine. Both TF1 and TF2 were easier accumulated in brain $\left(p<0.05\right.$ in 40 and $200 \mathrm{mg} / \mathrm{kg}^{\text {bw }}$. d).
It was reported that TF could induce neurobehavioural effects in rodents. The possible reason might be that TF could act as a dopamine transporter inhibitor and could act on the serotoninergic system (Gagnaire and Micillino, 2006; Perkins et al., 1991). The concentrations of TF1 and TF2 in absorptive organ (intestine) were higher than concentrations in metabolic organ (liver and kidney) in $40 \mathrm{mg} / \mathrm{kg}^{\mathrm{bw}}$. d group. However, opposite appearance were observed in $200 \mathrm{mg} / \mathrm{kg}^{\text {bw }}$. $\mathrm{d}$ group $(p<0.05)$. These results showed TF could be metabolized rapidly in low dose group. When the daily dosage exceeded a level beyond metabolic ability, accumulation would also occur in metabolic organs, indicating a substantial stereoselectivity on distribution of TF enantiomers in lizard. The concentrations of TN enantiomers in lizard were depended on the metabolic rate of TF and the degradation rate of themselves. All the four TN enantiomers were detected in all tissues while the residue of TN1, TN2 and TN3 
were very low. However, the TN4 concentrations did not show significant difference among the comparisons.

\subsection{Enantiomers bioaccumulation}

During bioaccumulation experiment, concentrations of TF1 and TF2 stayed low concentrations before day 10 but increased after then until day 35 sustainably both in blood and liver in low dose group (Fig. 4). The increases slowed down after 28 days. Concentrations of TF1 and TF2 first declined before day 3 but increased rapidly to the highest level at about 7-14 days in both the blood and liver in the high dose group. After 14 days of exposure, concentrations reached steady state for two enantiomers. Bioaccumulation of TF and TN enantiomers levels were time-dependent.

One-tailed correlation analysis was carried out to test the correlation of the means of TF concentrations in liver and blood. The results indicated that TF1 concentrations in liver had correlation with TF1 concentrations in blood $(r=0.824$ and $r=0.831$ in 40 and $200 \mathrm{mg} / \mathrm{kg}^{\mathrm{bw}} \cdot \mathrm{d}$, respectively, $p<0.01$ ), TF2 concentrations in liver had correlation with TF2 concentrations in blood $(r=0.905$ and $r=0.900$ in 40 and $200 \mathrm{mg} / \mathrm{kg}^{\mathrm{bw}}$. d, respectively, $\left.p<0.01\right)$. The concentrations of TF enantiomers in liver were consistent with variation of the concentrations in blood. One-way ANOVA test showed that concentrations of TF enantiomers in blood were significant higher than the concentrations in liver at first 14 days in both groups $(p<0.05)$. No significant differences were observed after 14 days $(p>0.05)$. TF enantiomers first absorbed by stomach and intestines then entered into blood. The enantiomers were transported to liver through blood circulation. TF enantiomers were slowly accumulated in liver. TF concentrations in blood were
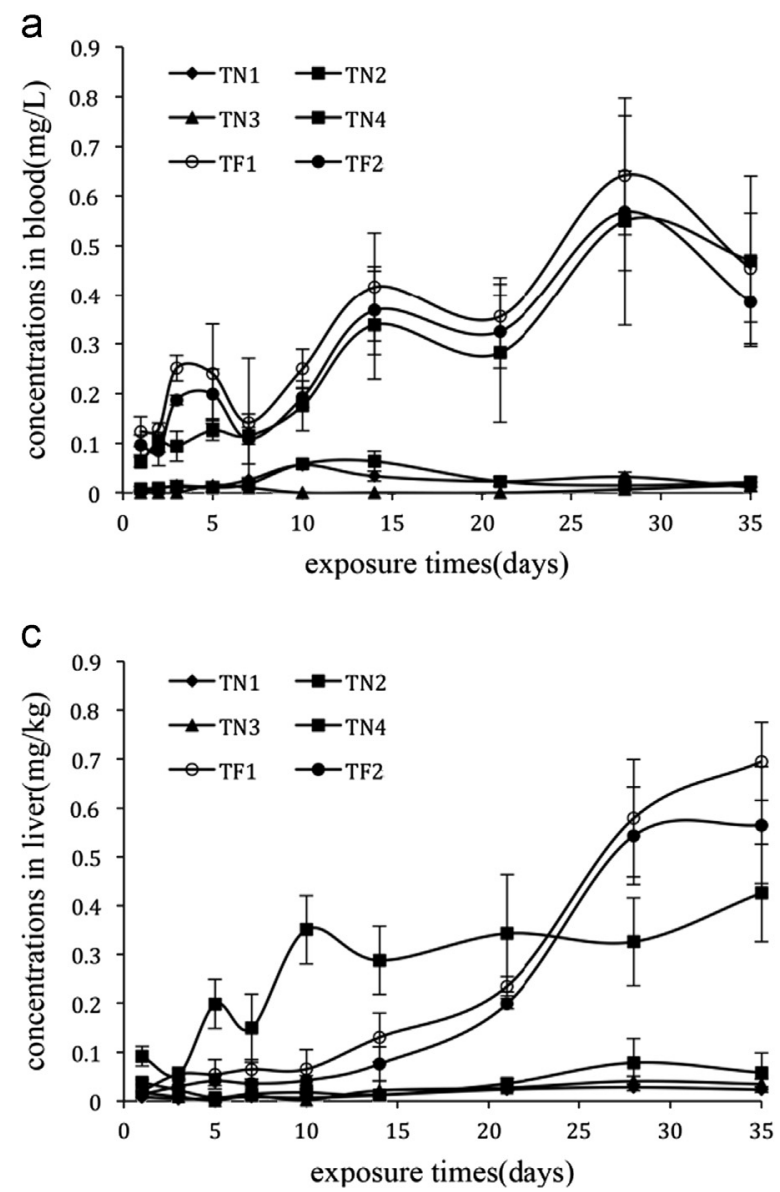

higher than TF concentrations in the liver at first. However, with the bioaccumulation of TF in liver, there were no significant differences between TF concentrations in liver and blood. The concentration of TF1 in liver was even higher than concentration in blood in $40 \mathrm{mg} / \mathrm{kg}^{\mathrm{bw}} \cdot \mathrm{d}(p=0.036)$ group at the end of exposure.

A $t$-test was carried out to compare the means of the EF values in lizard bloods and livers with $\mathrm{EF}(\mathrm{TF} 1)=0.5$ and $\mathrm{EF}(\mathrm{TN} 4)=0.1$. Concentrations of TF1 were higher than TF2 in the blood and the liver in both groups. The average $\operatorname{EF}(\mathrm{TF} 1)$ was $0.549(p<0.001)$ in blood and average EF(TF1) was $0.590(p<0.001)$ in liver in low dose group. The average $\operatorname{EF}(\mathrm{TF} 1)$ was $0.544(p<0.001)$ in blood and average $\mathrm{EF}(\mathrm{TF} 1)$ was $0.622(p=0.004)$ in liver in high dose group. The bioaccumulation behavior of TF was enantioselective. The EF(TF1)s in liver was higher than EF(TF1)s in blood, this result indicated that liver might be the main organ where enantioselective behavior occurred. Concentrations of metabolic product TN4 were much higher than other three enantiomers. The average EF (TN4) was $0.791(p<0.001)$ in blood and average $\operatorname{EF}(\mathrm{TN} 4)$ was $0.779(p<0.001)$ in liver in low dose group. The average EF(TN4) was $0.678(p<0.001)$ in blood and average $\mathrm{EF}(\mathrm{TN} 4)$ was 0.712 $(p<0.001)$ in liver in high dose group. The metabolic processes of TF and bioaccumulation behavior of TN were enantioselective. The $\mathrm{EF}(\mathrm{TN} 4) \mathrm{s}$ in low dose group were higher than EF(TN4)s in high dose group in blood (a paired-samples $t$-test, $p=0.009$ ) and liver (a paired-samples $t$-test, $p=0.015$ ), respectively. The possible cause of decline of EF(TN4)s might be the bioaccumulation of TN2 in high dose group. On the contrary, concentrations of TN2 showed negative correlation with concentrations of TN4 both in blood $(r=-0.775, p=0.024)$ and liver $(r=-0.834, p=0.02)$ in high dose group after day 5 . TN2 and TN4 were pair metabolites of

\section{b}
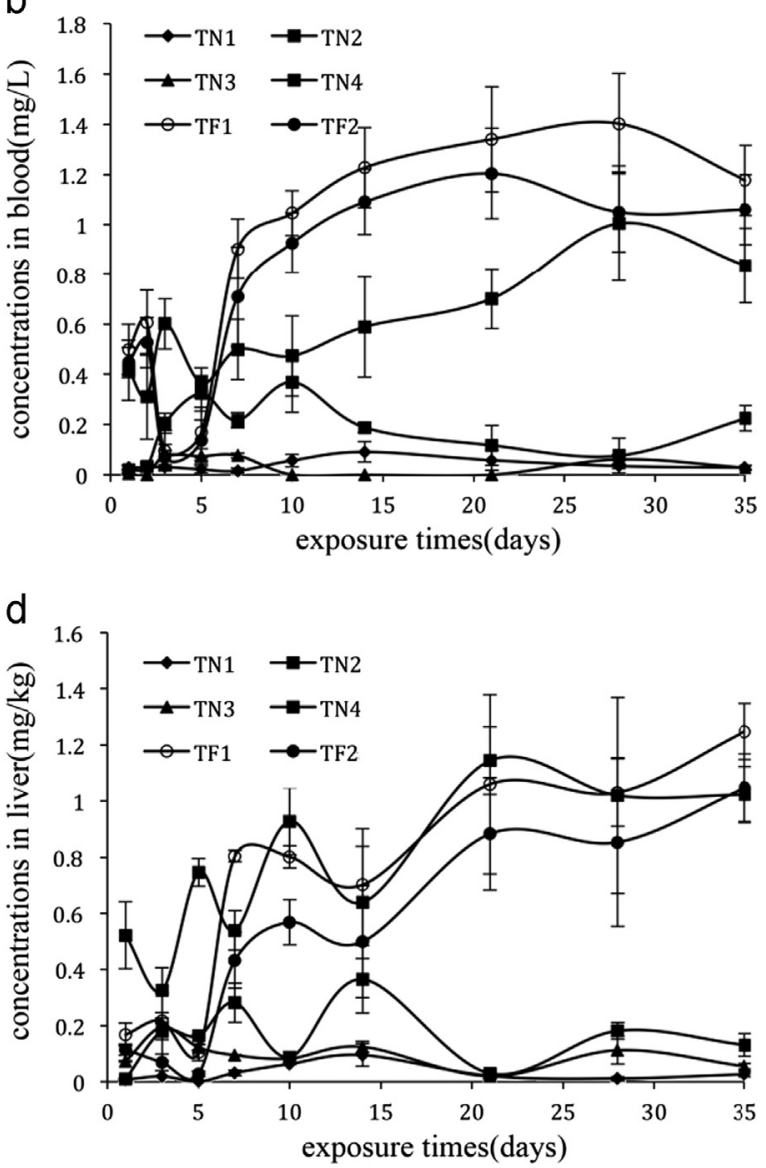

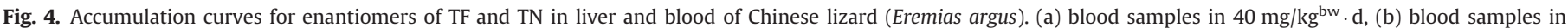
$200 \mathrm{mg} / \mathrm{kg}^{\mathrm{bw}} \cdot \mathrm{d}$, (c) liver samples in $40 \mathrm{mg} / \mathrm{kg}^{\mathrm{bw}} \cdot \mathrm{d}$, (d) liver samples in $200 \mathrm{mg} / \mathrm{kg}^{\mathrm{bw}} \cdot \mathrm{d}$ 
TF2. The chiral conversion between enantiomers of TN, especially chiral conversion between TN2 and TN4 might be the possible reason caused the negative correlation between TN2 and TN4 and the decline of $\mathrm{EF}(\mathrm{TN} 4) \mathrm{s}$ in high dose group.

\subsection{Chronic effects on lizard}

Signs of toxicity in chronic bioaccumulation experiment were similar to the subacute study, though more subtle, and were best characterized as anorexia and generalized, progressive lethargy.

Movement and food consumed were recovered at first week but reduced again after about 2 weeks. Only one lizard died in $40 \mathrm{mg} / \mathrm{kg}^{\text {bw }} \cdot \mathrm{d}$ group, but 17.5 percent mortality was observed in $200 \mathrm{mg} / \mathrm{kg}^{\text {bw }}$. $\mathrm{d}$ group. Changes in body weight (m) and wet ratio of liver ( $r$ ) over exposure time were studied (Supporting Information, Fig. S3). Significant losses of body weight in both dose groups were observed (a paired-samples $t$-test, $p=0.030$ and $p=0.018$ in 40 and $200 \mathrm{mg} / \mathrm{kg}^{\mathrm{bw}}$. d, respectively). Lizards lost an average of 22.32 and 31.75 percent body weight in 40 and $200 \mathrm{mg} /$ $\mathrm{kg}^{\mathrm{bw}}$. d group, respectively. The wet ratio of liver was significantly increased compared to the controls (a paired-samples $t$-test, $p=0.043$ and $p=0.019$ in 40 and $200 \mathrm{mg} / \mathrm{kg}^{\mathrm{bw}}$. d, respectively) and showed a clear response to dose $(p=0.029)$. The wet ratio of liver increased by 49.0 and 72.1 percent in 40 and $200 \mathrm{mg} / \mathrm{kg}^{\text {bw }} \cdot \mathrm{d}$, respectively. Hepatic histological lesions might be coursed during the exposure. No differences in wet ratio of other organs were found $(p>0.05)$.

\subsection{Restoring experiment}

Lizards were continuously dosed in the first 14 days and then fed normally for another 14 days in restoring experiment. Concentrations of TF1, TF2, and TN4 declined sharply in the first 3 days during the normal feeding. Concentrations of TN1, TN2, and TN3 stayed low values. The concentrations level of all enantiomers reduced to very low values $(<0.005 \mathrm{mg} / \mathrm{kg}$ ) after 7 days. These results suggested that concentrations of TF and TN could be metabolized rapidly in lizard blood and liver.

Lizards lost an average of 12.47 percent body weight at day 7 but recovered to 11.33 percent at day 14 in $40 \mathrm{mg} / \mathrm{kg}^{\text {bw }}$. d group. Lizards lost an average of 15.75 percent body weight at day 7 and 28.32 percent at day 14 in $200 \mathrm{mg} / \mathrm{kg}^{\text {bw }}$. d group. Foods consumption was recovered in low dose group. However, anorexia and lethargy were still observed in high dose group. No lizard died in low dose group but 12 percent (3/25) mortality was observed in high dose group. These results indicated that concentrations level of all enantiomers could be reduced rapidly in both group, but the damages to lizards were difficult to restore in high dose group.

\section{Conclusions}

According to the findings of this study, both the parent compound TF and its metabolic product TN could be metabolized rapidly in lizard. TF had been tested as low acute oral toxicity to E. argus in our study. The bioaccumulation of TF and TN enantiomers can still be observed even under the continuously low-dose exposure. During the chronic exposure, the wet ratio of liver was significantly increased and showed a clear response to dose which meant hepatic histological lesions might be caused. These indicated that the low residual of TF and TN in the environment could also be a threat to the lizard and other animals living in the soil. According the results in restoring experiment, concentrations level of all enantiomers could be reduced rapidly, but the signs of intoxication and foods consumption still could not be recovered in a short period.
In this study, we also observed stereoselectivity of TF and TN enantiomers occurred in all the processes of metabolism, distribution, and bioaccumulation of TF and TN in lizard. To achieve the complete understanding of the effects of TF on Chinese lizard, efforts should focus on analyzing the effects of individual enantiomer of these two compounds.

\section{Acknowledgments}

The National High Technology Research and Development Program (863) of China (No. 2012AA06A3025) supported this work and National Natural Science Foundation of China (Contract Grant no. 21277163 and no. 41301569). We thank Mr. Edward Lang and Dr. Xiaoyi Wang for helping revise the paper.

\section{Appendix A. Supporting information}

Supplementary data associated with this article can be found in the online version at http://dx.doi.org/10.1016/j.ecoenv.2014.06.021.

\section{References}

Bromilow, R.H., Evans, A.A., Nicholls, P.H., 1999. Factors affecting degradation rates of five triazole fungicides in two soil types: 1 . Laboratory incubations. Pest. Sci. 55, 1129-1134.

Buono, S., Cristiano, L., D'angelo, B., Cimini, A., Putti, R., 2007. PPAR $\alpha$ mediates the effects of the pesticide methyl thiophanate on liver of the lizard Podarcis sicula. Comp. Biochem. Physiol. C: Toxicol. Pharmacol. 145, 306-314.

Buser, H.-R., Müller, M.D., Poiger, T., Balmer, M.E., 2002. Environmental behavior of the chiral acetamide pesticide metalaxyl: enantioselective degradation and chiral stability in soil. Environ. Sci. Technol. 36, 221-226.

Crowell, S.R., Henderson, W.M., Kenneke, J.F., Fisher, J.W., 2011. Development and application of a physiologically based pharmacokinetic model for triadimefon and its metabolite triadimenol in rats and humans. Toxicol. Lett. 205, 154-162.

De Falco, M., Sciarrillo, R., Capaldo, A., Russo, T., Gay, F., Valiante, S., Varano, L., Laforgia, V., 2007. The effects of the fungicide methyl thiophanate on adrenal gland morphophysiology of the lizard, Podarcis sicula. Arch. Environ. Contam. Toxicol. 53, 241-248.

Deas, A., Carter, G., Clark, T., Clifford, D., James, C., 1986. The enantiomeric composition of triadimenol produced during metabolism of triadimefon by fungi: III. Relationship with sensitivity to triadimefon. Pestic. Biochem. Physiol. $26,10-21$.

Di Renzo, F., Corsini, E., Broccia, M., Marinovich, M., Galli, C., Giavini, E., Menegola, E., 2009. Molecular mechanism of teratogenic effects induced by the fungicide triadimefon: study of the expression of TGF- $\beta$ mRNA and TGF- $\beta$ and CRABPI proteins during rat in vitro development. Toxicol. Appl. Pharmacol. 234 107-116.

Dong, F., Li, J., Chankvetadze, B., Cheng, Y., Xu, J., Liu, X., Li, Y., Chen, X., Bertucci, C. Tedesco, D., 2013. Chiral triazole fungicide difenoconazole: absolute stereochemistry, stereoselective bioactivity, aquatic toxicity, and environmental behavior in vegetables and soil. Environ. Sci. Technol. 47, 3386-3394.

Feder, P., Hobson, D., Olson, C., Joiner, R., Matthews, M., 1991. Stagewise, adaptive dose allocation for quantal response dose-response studies. Neurosci. Biobehav. Rev. 15, 109-114.

Gagnaire, F., Micillino, J.-C., 2006. Effects of triadimefon on extracellular dopamine, DOPAC, HVA and 5-HIAA in adult rat striatum. Toxicology 217, 91-104.

Garrison, A.W., Avants, J.K., Jones, W.J., 2011. Microbial transformation of triadimefon to triadimenol in soils: selective production rates of triadimenol stereoisomers affect exposure and risk. Environ. Sci. Technol. 45, 2186-2193.

Gibbon, J.W., Scott, D.E., Ryan, T.J., Buhlmann, K.A., Tuberville, T.D., Metts, B.S., Greene, J.L., Mills, T., Leiden, Y., Poppy, S., 2000. The global decline of reptiles, Déjà Vu Amphibians: reptile species are declining on a global scale. Six significant threats to reptile populations are habitat loss and degradation, introduced invasive species, environmental pollution, disease, unsustainable use, and global climate change. BioScience 50, 653-666.

Holem, R.R., Hopkins, W.A., Talent, L.G., 2008. Effects of repeated exposure to malathion on growth, food consumption, and locomotor performance of the western fence lizard (Sceloporus occidentalis). Environ. Pollut. 152, 92-98.

Hopkins, W.A., 2000. Reptile toxicology: challenges and opportunities on the last frontier in vertebrate ecotoxicology. Environ. Toxicol. Chem. 19, 2391-2393.

Keller, J.M., McClellan-Green, P.D., Kucklick, J.R., Keil, D.E., Peden-Adams, M.M. 2006. Effects of organochlorine contaminants on loggerhead sea turtle immunity: comparison of a correlative field study and in vitro exposure experiments. Environ. Health Perspect. 114, 70-76.

Kellock,K.,Overmyer,J.,Garrison,A.W.,Avants,J.K., 2009. Toxicity of triadimefon racemate and enantiomers to black fly larvae. In: SETAC North America 30th Annual Meeting, New Orleans, LA, 296-297. 
Kenneke, J.F., Ekman, D.R., Mazur, C.S., Konwick, B.J., Fisk, A.T., Avants, J.K., Garrison, A.W., 2010. Integration of metabolomics and in vitro metabolism assays for investigating the stereoselective transformation of triadimefon in rainbow trout. Chirality 22, 183-192.

Li, Y., Dong, F., Liu, X., Xu, J., Han, Y., Zheng, Y., 2014. Chiral fungicide triadimefon and triadimenol: stereoselective transformation in greenhouse crops and soil and toxicity to Daphnia magna. J. Hazard. Mater. 265, 115-123.

Li, Z., Zhang, Y., Li, Q., Wang, W., Li, J., 2011. Enantioselective degradation, abiotic racemization, and chiral transformation of triadimefon in soils. Environ. Sci. Technol. 45, 2797-2803.

Liang, H., Li, L., Qiu, J., Li, W., Yang, S., Zhou, Z., Qiu, L., 2013. Stereoselective transformation of triadimefon to metabolite triadimenol in wheat and soil under field conditions. J. Hazard. Mater. 260, 929-936.

Liang, H., Qiu, J., Li, L., Li, W., Zhou, Z., Liu, F., Qiu, L., 2012. Stereoselective separation and determination of triadimefon and triadimenol in wheat, straw, and soil by liquid chromatography-tandem mass spectrometry. J. Sep. Sci. 35, 166-173.

Lin, L., Yutao, Z., Jinzhong, Z., 2008. Research progress on the residue analysis of triazole pesticides. J. Anhui Agric. Sci. 36 (22), 9704-9707.

Mann, R.M., Sánchez-Hernández, J.C., Serra, E.A., Soares, A.M., 2007. Bioaccumulation of $\mathrm{Cd}$ by a European lacertid lizard after chronic exposure to $\mathrm{Cd}$ contaminated food. Chemosphere 68, 1525-1534.

McFarland, C.A., Quinn Jr, M.J., Boyce, J., LaFiandra, E.M., Bazar, M.A., Talent, L.G. Johnson, M.S., 2011. Toxic effects of oral 2-amino-4,6-dinitrotoluene in the western fence lizard (Sceloporus occidentalis). Environ. Pollut. 159, 466-473.

McFarland, C.A., Quinn, M.J., Bazar, M.A., Talent, L.G., Johnson, M.S., 2009. Toxic effects of oral hexahydro-1,3,5-trinitro-1,3,5-triazine in the western fence lizard (Sceloporus occidentalis). Environ. Toxicol. Chem. 28, 1043-1050.

Menegola, E., Broccia, M.L., Di Renzo, F., Prati, M., Giavini, E., 2000. in vitro teratogenic potential of two antifungal triazoles: triadimefon and triadimenol in vitro Cell. Dev. Biol. Anim. 36, 88-95.

Moss, S., Keller, J.M., Richards, S., Wilson, T.P., 2009. Concentrations of persistent organic pollutants in plasma from two species of turtle from the Tennessee River Gorge. Chemosphere 76, 194-204.

Organization for Economic Cooperation and Development (OECD), 1984. OECD Guidelines for the Testing of Chemicals. Test Guideline 205: Avian Dietary Toxicity Test (adopted April 1984). Paris, France.

Perkins, A.N., Eckerman, D.A., MacPhail, R.C., 1991. Discriminative stimulus properties of triadimefon: comparison with methylphenidate. Pharmacol. Biochem. Behav. 40, 757-761.

Petrovic, A.M., Young, R.G., Ebel Jr, J.G., Lisk, D.J., 1993. Conversion of triadimefon fungicide to triadimenol during leaching through turfgrass soils. Chemosphere 26, 1549-1557.

Randhawa, M.A., Anjum, M.N., Butt, M.S., Yasin, M., Imran, M., 2014. Minimization of imidacloprid residues in cucumber and bell pepper through washing with citric acid and acetic acid solutions and their dietary intake assessment. Int. J. Food Prop. 17, 978-986.

Reeves, R., Thiruchelvam, M., Cory-Slechta, D., 2004. Expression of behavioral sensitization to the cocaine-like fungicide triadimefon is blocked by pretreatment with AMPA, NMDA and DA D1 receptor antagonists. Brain Res. 1008, 155-167.

Reeves, R., Thiruchelvam, M., Richfield, E.K., Cory-Slechta, D.A., 2003. Behavioral sensitization and long-term neurochemical alterations associated with the fungicide triadimefon. Pharmacol. Biochem. Behav. 76, 315-326.

Roberts, T.R., Hutson, D.H., 1999. Metabolic Pathways of Agrochemicals: Part 2, Insecticides and Fungicides. Royal Society of Chemistry.

Simoniello, P., Filosa, S., Riggio, M., Scudiero, R., Tammaro, S., Trinchella, F., Motta, C. M., 2010. Responses to cadmium intoxication in the liver of the wall lizard Podarcis sicula. Comp. Biochem. Physiol. C: Toxicol. Pharmacol. 151, 194-203.

Singh, N., 2005. Factors affecting triadimefon degradation in soils. J. Agric. Food Chem. 53, 70-75.

Spindler, F., Fruh, T., 1998. Chiral acylanilides and chiral triazole-related fungicides. Chirality Agrochem., 143-145.

Suski, J.G., Salice, C. Houpt, J.T., Bazar, M.A., Talent, L.G., 2008. Dose-related effects following oral exposure of 2,4-dinitrotoluene on the western fence lizard, Sceloporus occidentalis. Environ. Toxicol. Chem. 27, 352-359.

Trinchella, F., Riggio, M., Filosa, S., Volpe, M.G., Parisi, E., Scudiero, R., 2006 Cadmium distribution and metallothionein expression in lizard tissues following acute and chronic cadmium intoxication. Comp. Biochem. Physiol. C: Toxicol. Pharmacol. 144, 272-278.

Ulrich, E.M., Morrison, C.N., Goldsmith, M.R., Foreman, W.T., 2012. Chiral pesticides: identification, description, and environmental implications. Rev. Environ. Contam. Toxicol. 217, 1-74.

U.S. Environmental Protection Agency (U.S. EPA), 1996a. Ecological Effects Test Guidelines, OPPTS 850.2100, Avian Acute Oral Toxicity Test, Washington, DC: U. S. EPA. U.S. EPA 712-C-96-139.

U.S. Environmental Protection Agency (U.S. EPA), 1996b. Ecological Effects Test Guidelines, OPPTS 850.2200, Avian Dietary Toxicity Test, Washington, DC: U.S. EPA. EPA 712-C-96-140.

U.S. Environmental Protection Agency (U.S. EPA), 2006. Reregistration Eligibility Decision for Triadimefon and Tolerence Reassessment for Triadimenol, EPA 738-R-06-003, U.S. Environmental Protection Agency, Washington,DC.

van de Merwe, J.P., Hodge, M., Olszowy, H.A., Whittier, J.M., Lee, S.Y., 2010. Using blood samples to estimate persistent organic pollutants and metals in green sea turtles (Chelonia mydas). Mar. Pollut. Bull. 60, 579-588.

Walker, Q.D., Lewis, M.H., Crofton, K.M., Mailman, R.B., 1990. Triadimefon, a triazole fungicide, induces stereotyped behavior and alters monoamine metabolism in rats. Toxicol. Appl. Pharmacol. 102, 474-485.

Weir, S.M., Suski, J.G., Salice, C.J., 2010. Ecological risk of anthropogenic pollutants to reptiles: evaluating assumptions of sensitivity and exposure. Environ. Pollut. 158, 3596-3606.

Williams, A., 1996. Opportunities for chiral agrochemicals. Pest. Sci. 46, 3-9.

Wong, C.S., 2006. Environmental fate processes and biochemical transformations of chiral emerging organic pollutants. Anal. Bioanal. Chem. 386, 544-558.

World Health Organization, 2006. Evaluations 2004, Part II-Toxicological WHO Pesticide Residues in Food. WHO, Geneva, Switzerland. 